\title{
Recruitment into old age psychiatry
}

\author{
Lynsey McAlpine, ${ }^{1,2}$ Alex Bailey, ${ }^{3,4}$ Kate Milward, ${ }^{5,6}$ Charlotte Blewett $^{6,7}$
}

BJPsych Bulletin (2019) 43, 131-135, doi:10.1192/bjb.2018.112

\begin{abstract}
Medical Education Department, East London NHS Foundation Trust, UK; ${ }^{2}$ Centre for Psychiatry, Barts and the London School of Medicine and Dentistry, UK; ${ }^{3}$ Old Age Psychiatry, Central and North West London NHS Foundation Trust, UK; ${ }^{4}$ Faculty of Old Age Psychiatry Royal College of Psychiatrists, UK; ${ }^{5}$ Old Age Psychiatry, Birmingham and Solihull Mental Health NHS Foundation Trust, UK; ${ }^{6}$ Psychiatric Trainees Committee, Royal College of Psychiatrists, UK; ${ }^{7}$ Old Age Psychiatry and General Adult Psychiatry, Sheffield Health and Social Care NHS Foundation Trust, UK

Correspondence to Dr Lynsey McAlpine (lynseymcalpine@nhs.net)

First received 12 Jun 2018, final revision 9 Oct 2018, accepted 20 Nov 2018

(C) The Authors 2019. This is an Open Access article, distributed under the terms of the Creative Commons Attribution-NonCommercial-ShareAlike licence (http://creativecommons.org/ licenses/by-nc-sa/4.0/), which permits non-commercial re-use, distribution, and reproduction in any medium, provided the same Creative Commons licence is included and the original work is properly cited. The written permission of Cambridge University Press must be obtained for commercial re-use.
\end{abstract}

This research aimed to explore the trainee perspective on factors affecting recruitment into old age psychiatry higher training in the UK. A qualitative survey was created by the Faculty of Old Age Psychiatry and distributed to current higher trainees in all psychiatric subspecialties. A total of 324 higher trainees responded to the survey, representing a broad demographic range. Thematic analysis was carried out, with sufficient responses to achieve saturation. Key themes included concerns about the future of the specialty, issues with social care, lack of support with patients' physical health needs, issues with training posts, and workload. The need to improve core trainees' experience of the specialty was highlighted. Many positive themes arose from the data; however, a number of barriers to recruitment were also identified. The findings have implications for recruitment to the specialty and should be used to inform recruitment strategy moving forward.

\section{Declaration of interest None.}

Keywords Education and training; qualitative research; recruitment; old age psychiatry.
Old age psychiatry is a relatively new specialty: in the UK it first appeared in the 1950s, and gained ascendancy in subsequent decades with establishment of the Royal College of Psychiatrists (RCPsych) Faculty of the Psychiatry of Old Age in 1973, and the introduction of consultant-led multidisciplinary teams. ${ }^{1}$ A total of $18 \%$ of the UK population are aged 65 years and over, and $2.4 \%$ are aged 85 years and over, and it is projected that the older-adult population will continue to increase. $^{2}$ With this ageing population, there is increasing need for specialist teams that cater for the physical, psychological, cognitive and social needs unique to older people with mental illness; despite this, the specialty is under threat. ${ }^{3}$

Concurrently, the specialty is facing a growing recruitment problem. An estimated $45 \%$ increase in consultant numbers is required by 2033; however, it is predicted that consultant numbers will actually decrease by $7 \%$ over this period. ${ }^{4}$ These recruitment difficulties are not unique to the UK: similar issues have been described across Europe and the USA. ${ }^{5}$ The reasons for this loss of consultant stock are multiple, including the final cohort of those consultants retiring with enhanced pension rights, but there is also a clear trend of decreased training within the specialty. In the August 2016 recruitment round, only $36 \%$ of vacancies in old age psychiatry (as a single subspecialty) were filled at ST4 level; the lowest of all the subspecialties (although dual old age and general adult training fared better, at $62 \%){ }^{6}$

This disconnect between supply and demand is one of the most substantial threats to the future of the specialty. To address this, it is necessary to understand the incentives and barriers to training in old age psychiatry. This survey was designed and administered by the Faculty of Old Age Psychiatry within RCPsych to explore these factors as part of its overall strategic aim of improving recruitment within the specialty.

\section{Method}

\section{Setting}

The target population for this research was identified as current UK trainees undertaking higher training in any of the psychiatric subspecialties. 


\section{Ethical considerations}

The research was approved by the RCPsych Workforce and Training department. Before completion of the survey, participants were provided with information about the purpose of the study and how the data would be used. Completion of the questionnaire was taken as implied consent to participate in the study.

\section{Data protection}

Participants were asked to provide an email address if they wished to participate in the prize draw; they were informed that they could opt out of providing this information. Email addresses were not linked to the analysis of results and were stored on a password-protected survey site. No other identifiable information was collected.

\section{Survey design}

An adaptive questionnaire was developed with three versions for three separate categories of trainees based on their intended subspecialty: old age psychiatry, dual general adult and old age psychiatry and non-old age psychiatry. Each version covered the same topics, with the questions phrased differently depending on the trainees' intended subspecialty. The survey was created with SurveyMonkey, and consisted of nominal, ordinal and free-text questions. It was peerreviewed by higher trainees and consultant psychiatrists, including representatives from the RCPsych Faculty of Old Age Psychiatry, to assess technical functionality and content validity. Feedback from this pilot was used to iteratively refine the survey design.

\section{Survey distribution}

This was an open, voluntary survey. A link to the survey was advertised on the login page of the RCPsych trainee portfolio, along with an explanation about the purpose of the survey. The portfolio website was considered appropriate as all current higher trainees have access to this site and are expected to use it frequently; as such, an advertisement here was unlikely to pre-select a particular sample or have undue influence on the results. The advertisement remained in place throughout the 8-week data collection period, from February to March 2017. An email reminder was also sent out to all higher trainees currently registered with RCPsych. A prize draw for a $£ 200$ gift certificate was offered as an incentive.

\section{Response rate}

The number of unique site visitors was determined by IP address. Completion rate was $97 \%$. Qualitative data from incomplete questionnaires were included in the analysis.

\section{Analysis}

A preliminary analysis of the free-text responses was carried out by K.M. and C.B. to identify key themes arising from the data. Subsequently, the qualitative free-text responses were imported into NVivo and an independent thematic analysis was carried out by L.M., using an inductive coding method.
The analysis was based on four broad categories: reasons for choosing to train in old age psychiatry, reasons against training in old age psychiatry, reasons for choosing dual training and trainees' impressions about what needs to change to make old age psychiatry a more appealing training scheme. Key themes were identified and coded, and the data-set was reviewed in an iterative fashion to identify, refine and name the themes that emerged.

\section{Results and Discussion}

\section{Respondent demographics}

Of the 1550 higher trainees currently registered with RCPsych, a total of 324 completed the survey ( $21 \%$ of all current UK higher trainees); this response rate was sufficient to achieve saturation in the thematic analysis. Respondent demographics are summarised in Tables 1-3 below.

\section{Thematic analysis}

Reasons for choosing to train in old age psychiatry Key themes arose predominantly from dual and single old age psychiatry trainees, although a number of non-old age psychiatry trainees also reflected on their positive impressions about working in the specialty. By far the most prominent theme across both groups was that respondents enjoyed working with this patient group: 'most of all I like the patients'.

The challenge of working with complex cases was a frequently recurring positive theme: respondents enjoyed 'the detective role' and found the work to be 'hugely intellectually satisfying. In particular, respondents were positive about 'the interplay between medicine, psychiatry and neurology' and felt that working closely with other medical specialties 'helps to keep your knowledge of other specialties fresh and updated'.

Additionally, respondents were positive about their experiences of a 'holistic' and 'genuinely biopsychosocial' approach, which was enhanced by excellent multidisciplinary working: 'in old age psychiatry the teams I have worked with are the most cohesive... this is where I have seen the biopsychosocial model and good solid teamwork, communication and mutual support really come into play'. Several respondents commented that they particularly enjoyed working with organic illness; however, for many respondents, there was a clear preference for working with a 'mix of organic and functional presentations'.

Another theme that emerged from old age psychiatry respondents was the perception that old age psychiatry teams are empowered to have a significant effect on patients'

\begin{tabular}{|lc|}
\hline Table 1 & Training grade of respondents at time of survey \\
Training grade & $n(\%)$ \\
\hline ST4 & $120(37.04 \%)$ \\
\hline ST5 & $101(31.17 \%)$ \\
\hline ST6 & $89(27.47 \%)$ \\
\hline ST7 or higher & $14(4.32 \%)$ \\
\hline
\end{tabular}




\begin{tabular}{|lc|}
\hline Table 2 & Current subspecialty of respondents \\
\hline Psychiatric subspecialty & $n(\%)$ \\
\hline Old age & $65(20.06 \%)$ \\
\hline Dual general adult and old age & $62(19.14 \%)$ \\
\hline Other & $196(60.49 \%)$ \\
\hline
\end{tabular}

lives: 'I like that there is so much you can do to help patients and their families. I think it is incredibly rewarding?. Respondents expressed optimism about prospects for future research and hoped that in the foreseeable future 'there may be a fundamental change in our ability to deal with dementia'.

\section{Reasons for choosing not to train in old age psychiatry}

The majority of themes here arose from the free-text responses of non-old age psychiatry trainees; additionally, a number of old age psychiatry trainees reflected on the reasons that their peers might have decided against the specialty.

Concerns about the future of the specialty featured prominently, with respondents expressing the belief that there is 'far too much of a drive towards ageless services', which will lead to erosion of the specialty so that 'old age psychiatry will become "psychiatry of dementia". This discouraged respondents from considering old age psychiatry as they felt that ageless services would 'narrow [their] options far too much'. Additionally, it was felt that the move toward ageless services had implications for future employment prospects: the 'vulnerability' and 'uncertainty' was a significant deterrent for a number of respondents: 'why train in a specialty when you are told that it is not going to exist in the near future [?]'.

\begin{tabular}{|lr|}
\hline Table 3 & Training region of respondents \\
\hline Higher training region & $n(\%)$ \\
\hline South London & $49(15.12 \%)$ \\
\hline Scotland & $47(14.51 \%)$ \\
\hline North Central and East London & $37(11.42 \%)$ \\
\hline North West London & $26(8.02 \%)$ \\
\hline North West & $25(7.72 \%)$ \\
\hline West Midlands & $24(7.41 \%)$ \\
\hline Yorkshire and the Humber & $23(7.10 \%)$ \\
\hline South West & $22(6.97 \%)$ \\
\hline East of England & $15(4.63 \%)$ \\
\hline North East & $12(3.70 \%)$ \\
\hline East Midlands & $10(3.09 \%)$ \\
\hline Wales & $10(3.09 \%)$ \\
\hline Thames Valley & $10(3.09 \%)$ \\
\hline Northern Ireland & $7(2.16 \%)$ \\
\hline Wessex & $5(1.54 \%)$ \\
\hline Kent, Surrey and Sussex & $2(0.62 \%)$ \\
\hline
\end{tabular}

Several themes related to the perceived difficulties of working in old age psychiatry. It is 'renowned for being a stressful job' and there was an impression that it is harder to work part-time as a consultant compared with other psychiatric specialties. Availability of National Health Service and social care funding was a significant concern, and it was felt that this is likely to remain a longstanding problem: respondents commented on the impact of poor availability and quality of social care upon treatment decisions' and disliked 'not being able to offer optimal care due to lack of resources within social care'.

Another prominent theme was the lack of support available when dealing with physical health issues, experienced both during core training and higher training. This was described in very emotive terms as 'stressful', 'anxiety provoking', and 'overwhelming'. Respondents were discouraged by the concern that they would be 'used mainly as an amateur GP [general practitioner] on the wards' and felt that 'the lack of medics on the ward and the complete lack of physical health knowledge by nursing staff [makes] the wards feel so unsafe it was terrifying.

Negative perceptions about the specialty also influenced respondents' training decisions. Among non-old age psychiatry trainees the specialty was seen as 'uncool' and 'less sexy' than other areas of psychiatry, and 'the attitude it can evoke from other professionals' was off-putting.

\section{Dual training}

The responses from 62 dual trainees were examined to explore the reasons for choosing to dual train in old age psychiatry and general adult psychiatry. The overall perception was that dual training offered trainees much more flexibility in future job choices: respondents wanted to work in a variety of old age and general adult psychiatry posts as a consultant. It was seen as a good option for trainees who had not yet decided on their choice of specialty; it was also seen as a safer option in terms of job security, allowing trainees to 'hedge [their] bets either way ... if services became ageless'.

The other salient theme from these respondents was the belief that dual training offers a better 'all round training experience [which] will hopefully make me a better psychiatrist'. The longer duration of training was viewed as a positive, giving trainees opportunity to 'cover more subspecialties including neuropsychiatry' and develop a 'broad expertise'.

What needs to change to make the specialty more attractive Many respondents wrote lengthy and detailed comments about things that needed to change to improve the prospects of recruitment into the specialty. Non-old age psychiatry trainees reflected on what changes might have convinced them to train in old age psychiatry; old age psychiatry trainees discussed the issues that affect training decisions and considered the changes that might improve recruitment. A number of prominent points emerged.

Improve training experience. The most salient theme emerging from both old age psychiatry and non-old age psychiatry respondents was the need to improve the training experience for core and foundation trainees. It was felt that trainees at this level spend so much of their time investigating 
and managing physical health problems that they are 'missing out on ... more complex aspects of psychiatry of old age, exposure to which may be crucial in decision making about future career choices'. It was suggested that trainees 'should have protected time in clinics and doing domiciliary visits to see what higher trainees and consultants actually do' and that they are given opportunities to work in community mental health teams, memory services and liaison to gain a more accurate impression of the specialty. Moreover, there were calls to improve old age psychiatry teaching in core training, and for this to be reflected in the RCPsych Membership examinations.

The most frequently recurring suggestion for improving the training experience was the need for better support and resources to manage physical health conditions, particularly in in-patient settings. Physical health was seen as an exciting and integral part of old age psychiatry; however, trainees report feeling 'de-skilled' and 'daunted' by the expectation that they should be managing complex physical health conditions independently. There were numerous suggestions to reduce the physical health burden on junior doctors:

- Better links with geriatrics services and 'joint ward rounds with geriatricians';

- Close working with 'inreach GPs';

- 'employ more physical trained nurses on old age psychiatry wards';

- 'better access to the diagnostic tests and infrastructure available at the general hospital'.

Finally, it was felt that core and foundation trainees should have more exposure to positive role models and less exposure to negative ones. Some trainees were put off by the 'attitude of senior colleagues ... makes one feel unwanted [and] unappreciated'. Many respondents reflected on the importance of 'meeting inspirational consultants' and experiencing 'a trainer who was passionate about the specialty' who could offer 'support [and] career guidance'; 'Most other specialties were keen at recruiting trainees but this only seemed to be the case in old age if you'd worked with the TPD [Training Programme Director].'

Changes to higher training. Another emerging theme was the desire for changes to the higher training programme to make it more appealing to prospective trainees. Respondents expressed that there should be wider range of posts available to higher trainees, with a guarantee that there will be a mix of in-patient and out-patient posts available. In particular, respondents felt that there should be more dual training posts and greater flexibility in changing from single to dual Certificate of Completion of Training: at present 'there is a perception that there are a lot of obstacles to this'.

Respondents also advocated for a wider range of endorsements (particularly liaison and substance misuse) and dual training options. A number of respondents expressed an interest in dual training in old age psychiatry and psychotherapy; dual training in old age psychiatry and intellectual disabilities was also considered to be a viable options as 'the two specialties have a lot of overlap'.

Additionally, there was considerable appetite for more medical training, particularly in geriatrics, pharmacology, neurology and neuroimaging. Cross-specialty teaching was suggested as a way of establishing better links with colleagues in other specialties.

Reassurance about the future of old age psychiatry. 'The current generation of old age psychiatry consultants seem a bit gloomy about career prospects in the future'. Respondents felt that it was important for the RCPsych to address concerns about the future of the specialty: for old age psychiatry to be an appealing career choice, it was felt that 'trainees need to be reassured about job security' and that they need to see 'a concerted offense against "ageless" services'.

Additionally, respondents expressed that there was a clear need to 'rebrand' the specialty to address some of the negative stereotypes and preconceptions by 'making it loud and clear the specialty is not just about dementia'. Instead, it should be portrayed as a 'unique and individual specialty', offering an intellectually stimulating, varied and satisfying career.

\section{Recommendations}

Trainees in old age psychiatry appear to be committed to the specialty and derive enjoyment from their work within old age psychiatry. This research highlights factors that workforce strategists and RCPsych could exploit to highlight some of the attractions of working in old age psychiatry, in particular the concept of managing complexity and the 'detective' nature of the work, as well as the longestablished ethos of true multidisciplinary working within the specialty.

Physical health featured prominently within the survey, but in a complex way: trainees in old age psychiatry appear to value the obvious synergies in the specialty between mental and physical healthcare, but equally there was a strong sense that trainees felt insufficiently trained in more 'advanced' physical health capabilities and that much of the work, particularly at core training level, felt mundane and prevented them at times from experiencing the more psychiatric aspects of care. These complexities may also present opportunities, such as investigating ways of promoting the development of physical health skills and knowledge, perhaps by improving access to courses in geriatric medicine or creating shared-learning opportunities with geriatric or neurology colleagues.

Dual training appears to represent a measure of occupational security when it comes to applying for consultant roles. There has been a recent trend toward the merging of general and older adult services; ${ }^{7}$ evidence thus far suggests that these 'ageless' services are not equipped to meet the needs of older adults with functional mental illness, ${ }^{8}$ with detrimental effects on quality of care and patient safety. In the longer term, loss of dedicated old age services will result in the erosion of specialist knowledge and skills. ${ }^{9}$ Although there is anecdotal evidence that many trusts are reverting back to old age-specific services, it has clearly had an effect on how the specialty is perceived, including by trainees within old age psychiatry or considering it as a career. The Faculty of Old Age Psychiatry must consider how it can continue to oppose the rise of such services to help alleviate some of these concerns among the potential workforce and 
send an unequivocal message that old age psychiatry continues to be a highly relevant and vital specialty. There were also concerns that current training regulations feel restrictive at times, in terms of choosing a final Certificate of Completion of Training; it may be that educational bodies such as the RCPsych, local education training boards and regulators need to further examine whether these regulations are proportionate and fit for purpose in the changing workforce.

Current training in old age psychiatry must be overhauled to ensure it meets prospective trainees' needs. This analysis has highlighted that current training provision sometimes fails to emphasise the huge positives of working within the specialty; local education providers and the Faculty of Old Age Psychiatry should explore how training at core and foundation levels could be improved to better capture what trainees and consultants value about the specialty. It may be that old age psychiatry requires 'rebranding' to keep it relevant and exciting for potential trainees; research advances in dementia and the advent of the RCPsych neuroscience project should be harnessed and promoted by educationalists within old age psychiatry.

Recruitment in to core and higher psychiatric training remains a concern. The RCPsych recruitment strategy, including the recent Choose Psychiatry campaign, is intended to improve overall recruitment into psychiatric training. Reassuringly, the survey indicates that trainees who have chosen to train in old age psychiatry are happy about their choice of specialty and are positive about many aspects of their training. However, there are specialty-specific issues related to training in old age psychiatry that require a targeted approach to tackle the recruitment problem. This survey tallies with intelligence collected by the Faculty of Old Age Psychiatry and provides information 'from the source' about how trainees, both within old age psychiatry and more generally in psychiatric training, regard the specialty. There is no 'magic bullet' to instantly improve recruitment in to old age psychiatry, but this survey has yielded valuable qualitative data that should be harnessed to combat some of the issues currently facing recruitment in to the specialty.

\section{About the authors}

Dr Lynsey McAlpine, Fellow for Medical Education, Medical Education Department, East London NHS Foundation Trust; and Centre for Psychiatry, Barts and the London School of Medicine and Dentistry, UK; Dr Alex Bailey Consultant Psychiatrist, Old Age Psychiatry, Central and North West London NHS Foundation Trust; and Specialty Advisory Committee Chair, Faculty of Old Age Psychiatry, Royal College of Psychiatrists, UK; Dr Kate Milward, Psychiatric Higher Trainee, Old Age Psychiatry, Birmingham and Solihull Mental Health NHS Foundation Trust; and Former Chair, Psychiatric Trainees Committee, Royal College of Psychiatrists, UK; Dr Charlotte Blewett, Psychiatric Higher Trainee, Old Age Psychiatry and General Adult Psychiatry, Sheffield Health and Social Care NHS Foundation Trust; and Chair, Psychiatric Trainees Committee, Royal College of Psychiatrists, UK

\section{References}

1 Warner JP. Old age psychiatry in the modern age. Br J Psychiatry 2015; 207(5): 375-6.

2 Office for National Statistics (ONS). Overview of the UK Population: July 2017. ONS, 2017 (https://www.ons.gov.uk/peoplepopulationandcommunity/ populationandmigration/populationestimates/articles/overviewoftheukpopulation/july2017)

3 Saad K, Bangash A. Ageless mental health services and the future of old age psychiatry in the UK. J Geri Care Res 2016; 3(1): 21-3.

4 Centre for Workforce Intelligence (CFI). In-Depth Review of the Psychiatrist Workforce: Main Report. CFI, 2014 (http://webarchive.nationalarchives.gov. uk/20161007101116/http://www.cfwi.org.uk/publications/in-depth-reviewof-the-psychiatrist-workforce)

5 Brittlebank A, Hermans M, Bhugra D, Pinto da Costa M, Rojnic-Kuzman $M$, Fiorillo $A$, et al. Training in psychiatry throughout Europe. Eur Arch Psychiatry Clinl Neurosci 2016; 266: 155-64.

6 Health Education England (HEE). National Psychiatry Recruitment. HEE, 2017 (https://www.nwpgmd.nhs.uk/national_Psychiatry_Recruitment).

7 Warner JP. Wither old age psychiatry? Int Psychogeriatr 2014; 26(7): 1055-8.

8 Abdul-Hamid WK, Lewis-Cole K, Holloway F, Silverman AM. Comparison of how old age psychiatry and general adult services meet the needs of elderly people with functional mental illness: cross-sectional survey. Br J Psych 2015; 207(4): 1-4

9 Fisher J, Teodorczuck A. Old age psychiatry and geriatric medicine: shared challenges, shared solutions? Br J Psych 2017; 201(2): 91-3. 